\title{
The evaluation of right and left ventricular functions in children with episodic wheezing exposed to environmental tobacco smoke
}

\author{
Önder Doksöz¹, Hikmet Tekin Nacaroğlu², Gökhan Ceylan², Mehmet Çeleğen², \\ Şenay Aşık-Nacaroğlu ${ }^{3}$, Demet $\mathrm{Can}^{2}$, Timur Meşe ${ }^{1}$, Nurettin Ünal ${ }^{4}$ \\ Departments of ${ }^{1}$ Pediatric Cardiology, and ${ }^{2}$ Pediatric Allergy, Dr. Behcet Uz Children's Hospital, Izmir; ${ }^{3}$ Department of \\ Ophthalmology, Bağcllar Training and Research Hospital, Istanbul; ${ }^{4}$ Department of Pediatric Cardiology, Dokuz Eylül \\ University Faculty of Medicine, Izmir, Turkey. \\ E-mail: doksozonder@yahoo.com
}

Received: 11th January 2017, Accepted: 12th February 2017

SUMMARY: Doksöz Ö, Nacaroğlu HT, Ceylan G, Çeleğen M, Aşık-Nacaroğlu Ş, Can D, Meşe T, Ünal N. The evaluation of right and left ventricular functions in children with episodic wheezing exposed to environmental tobacco smoke. Turk J Pediatr 2017; 59: 42-48.

The objective of this study is to examine the right and left ventricular functions in children with episodic wheezing at the ages of 1-3 exposed to environmental tobacco smoke (ETS). Thirty-two children monitored at the Pediatric Allergy and Immunology Department of a Research and Training Hospital with the diagnosis of episodic wheezing were included. The prospective assessment of the patients was performed between May 2013 and February 2014. Twenty-five children with episodic wheezing not exposed to ETS formed the control group. The two groups were compared by conducting transthoracic two-dimensional and tissue Doppler echocardiography (TDE) examination in all of the cases. The average age of the study group ( 24 boys, 8 girls) was $33.1 \pm 8.8$ months, the average age of the control group (18 boys, 7 girls) was $31.9 \pm 11.9$ months. There was no statistically significant difference between the two groups in terms of age, gender, weight, height, and body mass index values. There was no statistically significant difference between the two groups for the right and left ventricular systolic and diastolic functions in the conventional echocardiographic measurements, and for the measurements of TDE. Limited number of patients is a major limitation of the study. These results should be supported by more comprehensive studies.

Key words: children, ventricular functions, wheezing.

Environmental tobacco smoke (ETS) indicates exposure to tobacco smoke, which originates not from an individual themselves smoking, but from other person's cigarette, cigar, or pipe smoke. It is also possible to characterize ETS, as the substance in indoor air arising from tobacco smoke. To breath in ETS is defined as passive smoking, second-hand smoke, or involuntary smoking ${ }^{1-5}$. In order to evaluate the ETS exposure, the urine cotinine measurement that is an easy, accurate and highly sensitive method is used in epidemiological studies. The determination of urine cotinine indicates more long-standing exposure than the determination of invasive serum cotinine ${ }^{2-6}$.
There is a connection of the chronic exposure to secondhand smoke (SHS) in children and a number of adverse health effects, such as an increase in the rates of sudden infant death syndrome, asthma, pneumonia, and impaired lung growth ${ }^{7}$. Although there are many studies showing the effect of the environmental tobacco smoke exposure on the vascular functions in children ${ }^{8-10}$, there are no studies showing its effects on the right and left ventricular functions. The objective of this study is to examine the right and left ventricular functions in children with episodic wheezing at the age of 1-3 exposed to ETS. 


\section{Material and Methods}

\section{Study population}

We prospectively evaluated the right and left ventricular systolic and diastolic functions in the cases exposed and not exposed to environmental tobacco smoke (ETS) and monitored in the allergy polyclinic of our hospital due to episodic wheezing. Patients were included in the study after the necessary permission had been acquired from the local ethics committee. Informed consent was acquired from the patients' families. The cases with episodic wheezing were included in the present study in accordance with the European Respiratory Society guidelines ${ }^{11}$. The measurement of urine cotinine levels was performed in order to identify ETS exposure and the cut-off value was selected as $10 \mathrm{ng} /$ $\mathrm{ml}$ in accordance with the literature ${ }^{12,13}$. Two hundred and thirty-seven patients with episodic wheezing were assessed to include into the study; receiving systemic or inhaler steroids or having familial history of early atherosclerosis, hypertension, diabetes, familial hyperlipidemia, chronic drug use history or obesity were the criteria for exclusion from the study. After the exclusion, 32 children exposed to ETS formed the study group and 25 children not exposed to ETS formed the control group.

\section{Laboratory studies}

An IMMULITE 2000 nicotine metabolite kit was used for the measurement of urinary cotinine levels in $\mathrm{ng} / \mathrm{ml}$ by means of an IMMULITE ${ }^{\circledR}$ 2000 (Siemens, USA) chemiluminescence assay. In accordance with the manufacturer's guidance, a $10 \mathrm{ng} / \mathrm{ml}$ value was accepted as the limit for ETS exposure. "No ETS exposure" was indicated by a value which was below 10 $\mathrm{ng} / \mathrm{ml}$ and "ETS exposure" was indicated by a value of $10 \mathrm{ng} / \mathrm{ml}$ or above.

\section{Echocardiographic examination}

A detailed standard Echo-Doppler cardiographic examination was performed in all patients and controls. A Vivid S6 (General Electric's Healthcare, Milwaukee, WI) with 4S-RS (1.7$4 \mathrm{MHz}$ ) probe incorporating two-dimensional (2D), color flow, spectral Doppler and pulsedwave tissue Doppler imaging (TDI) was used for performing echocardiographic measurements. Echocardiographic measurements were done when the patients were resting and in the supine position. Recording of the images on videotapes was performed. The measurements were done by the pediatric cardiology doctors. Conventional echocardiographic measurements were acquired in accordance with the instructions of the American Society of Echocardiography (ASE) ${ }^{14}$. Two-dimensional (2D) and M-mode measurements were acquired from parasternal long and short-axis images. Recording of minimum three successive beats in sinus rhythm was performed, and mean values were acquired. Recording of a mitral inflow velocity and tricuspid inflow velocity pattern was performed from an apical four-chamber image with a pulsed-wave Doppler sample volume which was placed at the edges of the mitral leaflets and tricuspid leaflets, respectively. LV and RV filling records were used for the measurement of peak early LV and RV filling velocity (E), peak late atrial filling velocity (A), and $\mathrm{E} / \mathrm{A}$ ratio. All measurements for diastolic indices were acquired in three successive cardiac cycles during the end expiration and for every measurement, the average values were calculated.

\section{Pulsed wave tissue Doppler imaging studies}

A special software package which is available on the Vivid S6 was used for pulsed wave TDI and it was conducted by performing the adjustment of the spectral pulsed Doppler signal filters in order to acquire a Nyquist limit of 15 to $20 \mathrm{~cm} / \mathrm{s}$ and with the minimal optimal gain. High-frame-rate (>150 frames/s) views were obtained in the tissue Doppler mode. The above-mentioned method can measure the ventricular wall motion velocity by placing the sample volume at the lateral edge of the mitral and tricuspid valve annuli. Attention was paid to acquire an ultrasound beam which was parallel to the direction of the annular motion. Recording of three successive images was performed. The average values obtained from these measurements were employed in the statistical analysis. All recordings were performed with a sweep speed of $100 \mathrm{~mm} / \mathrm{s}$, using a simultaneous electrocardiogram (lead II) at the above-mentioned positions and kept on the videotape for performing analysis in the future. The systolic myocardial velocity (Sa), the ejection time (ET), and the isovolumetric contraction time (IVCT) were employed as systolic parameters. The diastolic parameters 
Table I. Demographic Information of the Study and Control Groups.

\begin{tabular}{llll}
\hline Variables & $\begin{array}{l}\text { Study Group } \\
(\mathrm{n}: 32)\end{array}$ & $\begin{array}{l}\text { Control Group } \\
(\mathrm{n}: 25)\end{array}$ & p-value \\
\hline Age, month & $33.1 \pm 8.8$ & $31.9 \pm 11.9$ & 0.680 \\
Male/female & $24 / 8$ & $18 / 7$ & 0.800 \\
Weight, kg & $16.9 \pm 3.5$ & $16.4 \pm 4.7$ & 0.630 \\
Height, cm & $100.5 \pm 7.9$ & $98.3 \pm 8$ & 0.304 \\
Body mass index, kg/m ${ }^{2}$ & $16.6 \pm 2.1$ & $16.7 \pm 2.6$ & 0.843 \\
Systolic blood pressure, mmHg & $94.1 \pm 10.2$ & $92.6 \pm 10.6$ & 0.580 \\
Diastolic blood pressure, mmHg & $55.2 \pm 8.3$ & $52.9 \pm 6.7$ & 0.265 \\
Heart rate, bpm & $101.2 \pm 11.8$ & $101.4 \pm 12.8$ & 0.950
\end{tabular}

bpm: beat per minute

were as follows: the early diastolic myocardial velocity $(\mathrm{Ea})$, the late diastolic myocardial velocity at the time of atrial contraction $(\mathrm{Aa})$, the ratio of $\mathrm{Ea} / \mathrm{Aa}$ and the isovolumetric relaxation time (IVRT). The calculation of the ratio of Doppler-derived peak early mitral inflow velocity to tissue Doppler-derived peak early mitral annular velocity $(\mathrm{E} / \mathrm{Ea})$ was performed as a preload-independent index of LV filling pressures. The sum of isovolumetric relaxation time and isovolumetric contraction time which was divided by ejection time (IVRT+IVCT/ET) characterized the left ventricular myocardial performance index (MPI), being a global index of systolic and diastolic function. The measurement of Doppler time intervals was performed from mitral inflow and LV outflow tracing in accordance with the recommendations of Tei et al. ${ }^{15}$. Recording of the final velocities was performed for three cardiac cycles. The average values of the measurements were employed in the statistical analysis. The measurement of all parameters was performed at the end expiration and the measurement of three successive cardiac cycles was done and the average values for every measurement were calculated.

\section{Statistical analysis}

The SPSS package program version 18 was used for the statistical analyses. In order to identify whether the variables demonstrated normal distribution, their investigation with graphical and analytical methods was performed. The data were presented in the form of mean \pm standard deviation. In order to analyze the significance of pairwise differences, the Mann-Whitney U test was conducted. The chi-square test was conducted in order to compare the qualitative data along with the descriptive statistical methods. It was considered that an overall p-value below 0.05 demonstrated a statistical significance.

\section{Results}

The average age of the study group (24 boys, 8 girls) was $33.1 \pm 8.8$ months, the average age of the control group (18 boys, 7 girls) was $31.9 \pm 11.9$ months. There was no statistically significant difference between two groups in terms of age, gender, weight, height, body mass index, heart rate, systolic and diastolic blood pressure values (Table I). The demographic characteristics of each group are presented in Table I. There was no statistically significant difference in the conventional echocardiographic measurements between two groups in terms of the left ventricular M-mode measurements and left and right ventricular diastolic functions. The conventional echocardiography measurements are summarized in Table II. There was no statistically significant difference in the tissue Doppler measurements between two groups in terms of the right and left ventricular systolic and diastolic functions. The left ventricular tissue Doppler measurements are presented in Table III and the right ventricular tissue Doppler measurements are presented in Table IV.

\section{Discussion}

The tissue Doppler echocardiography (TDE) can diagnose the disruptions in the early phase during which the conventional echocardiography is normal ${ }^{16}$. In the study of Zeybek et al. ${ }^{17}$, it was found out that the conventional echocardiographic measurements 
Table II. Conventional Echocardiographic Measurements of the Study and Control Groups.

\begin{tabular}{llll}
\hline Variables & $\begin{array}{l}\text { Study Group } \\
(\mathrm{n}: 32)\end{array}$ & $\begin{array}{l}\text { Control Group } \\
(\mathrm{n}: 25)\end{array}$ & p-value \\
\hline LVIDd, cm & $3.20 \pm 0.35$ & $2.95 \pm 0.45$ & 0.034 \\
LVIDs, cm & $1.90 \pm 0.30$ & $1.80 \pm 0.16$ & 0.220 \\
EF, \% & $72.4 \pm 5.3$ & $72.6 \pm 5.5$ & 0.889 \\
FS, \% & $39.5 \pm 8.0$ & $40.6 \pm 4.7$ & 0.545 \\
Mitral inflow & & & \\
E max, cm/s & $107.6 \pm 16.6$ & $110.2 \pm 16.0$ & 0.541 \\
A max, cm/s & $68.0 \pm 11.4$ & $63.7 \pm 11.4$ & 0.163 \\
E/A & $1.6 \pm 0.30$ & $1.8 \pm 0.40$ & 0.069 \\
DT, ms & $129.8 \pm 49.5$ & $134.8 \pm 34.4$ & 0.650 \\
Tricuspid inflow & & & 0.675 \\
E max, cm/s & $64.9 \pm 11.6$ & $66.1 \pm 10.4$ & 0.064 \\
A max, cm/s & $61.7 \pm 14.2$ & $59.5 \pm 11.0$ & 0.061 \\
E/A & $1.1 \pm 0.3$ & $1.26 \pm 0.32$ & 0.075 \\
DT, ms & $114.5 \pm 29$ & $127.3 \pm 24.3$ & \\
\hline
\end{tabular}

EF: ejection fraction; FS: fractional shortening; LV: left ventricle; LVIDd and LVIDs: left ventricle internal diameter at end diastole and at end systole; A max: peak late atrial filling velocity; DT: deceleration time; E max: peak early left and right ventricle filling velocity; E/A: E/A ratio; ms: millisecond, s: second

Table III. Comparison of the Mitral Annulus Tissue Doppler Imaging Parameters.

\begin{tabular}{|c|c|c|c|}
\hline Variables & $\begin{array}{l}\text { Study Group } \\
(\mathrm{n}: 32)\end{array}$ & $\begin{array}{l}\text { Control Group } \\
(\mathrm{n}: 25)\end{array}$ & p-value \\
\hline \multicolumn{4}{|c|}{ Lateral mitral annulus } \\
\hline $\mathrm{Sa}, \mathrm{cm} / \mathrm{s}$ & $9.5 \pm 1.9$ & $9.4 \pm 1.1$ & 0.892 \\
\hline $\mathrm{Ea}, \mathrm{cm} / \mathrm{s}$ & $17.2 \pm 3.0$ & $17 \pm 3.0$ & 0.690 \\
\hline $\mathrm{Aa}, \mathrm{cm} / \mathrm{s}$ & $7.7 \pm 1.9$ & $8.4 \pm 2$ & 0.210 \\
\hline $\mathrm{Ea} / \mathrm{Aa}$ & $2.2 \pm 0.64$ & $2.15 \pm 0.66$ & 0.818 \\
\hline $\mathrm{E} / \mathrm{Ea}$ & $6.6 \pm 1.5$ & $6.5 \pm 1.7$ & 0.978 \\
\hline IVRT, ms & $47.7 \pm 6.6$ & $44.4 \pm 6.2$ & 0.056 \\
\hline IVCT, ms & $50.1 \pm 8.5$ & $50.2 \pm 9.9$ & 0.978 \\
\hline $\mathrm{ET}, \mathrm{ms}$ & $251.3 \pm 24.7$ & $254.8 \pm 23.1$ & 0.582 \\
\hline MPI, \% & $38.9 \pm 5.9$ & $36.6 \pm 5.6$ & 0.144 \\
\hline \multicolumn{4}{|c|}{ Medial mitral annulus } \\
\hline $\mathrm{Sa}, \mathrm{cm} / \mathrm{s}$ & $7.7 \pm 0.8$ & $7.8 \pm 0.8$ & 0.761 \\
\hline $\mathrm{Ea}, \mathrm{cm} / \mathrm{s}$ & $13.6 \pm 1.6$ & $14.6 \pm 2.2$ & 0.052 \\
\hline $\mathrm{Aa}, \mathrm{cm} / \mathrm{s}$ & $6.3 \pm 1.5$ & $6.9 \pm 1.9$ & 0.169 \\
\hline $\mathrm{Ea} / \mathrm{Aa}$ & $2.3 \pm 0.5$ & $2.2 \pm 0.5$ & 0.417 \\
\hline $\mathrm{E} / \mathrm{Ea}$ & $8.2 \pm 1.3$ & $7.5 \pm 1.6$ & 0.106 \\
\hline IVRT, ms & $45.5 \pm 6.0$ & $42.6 \pm 7.6$ & 0.110 \\
\hline IVCT, ms & $55.3 \pm 12.1$ & $50.2 \pm 8.0$ & 0.497 \\
\hline $\mathrm{ET}, \mathrm{ms}$ & $243.1 \pm 41.4$ & $249.2 \pm 20.9$ & 0.503 \\
\hline MPI, \% & $37.7 \pm 5.2$ & $37.1 \pm 5.6$ & 0.683 \\
\hline
\end{tabular}

Aa: late diastolic myocardial velocity; Ea: early diastolic myocardial velocity; Ea/Aa: $\mathrm{Ea} / \mathrm{Aa}$ ratio; E/Ea: the ratio of Doppler-derived peak early mitral inflow velocity (E) to tissue Doppler-derived peak early mitral annular velocity (Ea); ET: ejection time; IVCT: isovolumetric contraction time; IVRT: isovolumetric relaxation time; MPI: myocardial performance index; Sa: systolic myocardial velocity. 
Table IV. Comparison of the Right Ventricular Tissue Doppler Imaging Parameters.

\begin{tabular}{llll}
\hline Variables & $\begin{array}{l}\text { Study Group } \\
(\mathrm{n}: 32)\end{array}$ & $\begin{array}{l}\text { Control Group } \\
(\mathrm{n}: 25)\end{array}$ & p value \\
\hline $\mathrm{Sa}, \mathrm{cm} / \mathrm{s}$ & $14.1 \pm 2.3$ & $14.8 \pm 1.9$ & 0.199 \\
$\mathrm{Ea}, \mathrm{cm} / \mathrm{s}$ & $16.7 \pm 2.6$ & $18 \pm 2.9$ & 0.069 \\
$\mathrm{Aa}, \mathrm{cm} / \mathrm{s}$ & $11.5 \pm 3$ & $12.2 \pm 3.2$ & 0.371 \\
$\mathrm{Ea} / \mathrm{Aa}$ & $1.53 \pm 0.4$ & $1.6 \pm 0.3$ & 0.609 \\
$\mathrm{E} / \mathrm{Ea}$ & $4.0 \pm 0.8$ & $3.7 \pm 0.9$ & 0.130 \\
$\mathrm{IVRT}, \mathrm{ms}$ & $45.2 \pm 7.4$ & $46.5 \pm 8.5$ & 0.543 \\
$\mathrm{IVCT}, \mathrm{ms}$ & $48.4 \pm 7.9$ & $51.5 \pm 10.6$ & 0.221 \\
$\mathrm{ET}, \mathrm{ms}$ & $240.3 \pm 27.1$ & $244.9 \pm 25.1$ & 0.443 \\
MPI, \% & $39.1 \pm 5.2$ & $39.3 \pm 8.5$ & 0.879 \\
\hline
\end{tabular}

Aa: late diastolic myocardial velocity; Ea: early diastolic myocardial velocity; $\mathrm{Ea} / \mathrm{Aa}$ : $\mathrm{Ea} / \mathrm{Aa}$ ratio; $\mathrm{E} / \mathrm{Ea}$ : the ratio of Doppler-derived peak early mitral inflow velocity (E) to tissue Doppler-derived peak early mitral annular velocity (Ea); ET: ejection time; IVCT: isovolumetric contraction time; IVRT: isovolumetric relaxation time; MPI: myocardial performance index; Sa: systolic myocardial velocity.

were the same in children with mild asthma and healthy children, and in children with moderate and severe asthma; differences were detected in the tricuspid inflow parameters. In the same study, it was found out in the tissue Doppler measurements that the tricuspid lateral annular velocities and IVRT and medial and lateral mitral annular IVRT were different in children with mild asthma when compared to healthy children. Therefore, it was supposed that in the early period there was a subclinical ventricular diastolic dysfunction especially in the right ventricle in children with asthma and the level of the dysfunction was related to the severity of the lung disease. As in the study of Özdemir et al. ${ }^{18}$, it was shown in the study of Sheeded ${ }^{16}$ that although clinical and conventional echocardiographic findings were normal in children with asthma, it was correlated with TDE and subclinical RV dysfunction and the severity of the disease. TDE is superior to conventional echocardiography in identifying the subclinical dysfunctions in the early period ${ }^{16-18}$. Therefore, we employed both methods in the present study as in the studies mentioned above, however, no dysfunction was determined by both methods.

Repeated prolonged exposure to hypoxia with chronic inflammation in bronchial asthma causes stenosis in various oscillatory mediators, being main mechanisms, and cytokines pulmonary vasoconstriction and pulmonary veins ${ }^{16-20}$. As a result, right heart enlargement with ventricular hypertrophy and pulmonary hypertension causing disruptions in cardiac functions develop. When the high pressure becomes chronic, RV hypertrophy and dilatation result in systolic and diastolic dysfunction ${ }^{16-20}$. Episodic wheezing is a type of wheezing triggered by the viral upper respiratory infection and generally following an episodic course (>4-6 weeks). The most significant difference of it from persistent wheezing is that no symptoms are observed between 2 attacks. It is most commonly observed in preschool children. Although diagnostic tests are rarely conducted in clinical applications, there are clinical findings indicating its relationship with the viral respiratory infections ${ }^{11}$. We consider that since episodic wheezing attacks are rarer and more short-term when compared to asthma attacks, the mechanisms mentioned above cannot develop and therefore the right ventricular functions do not deteriorate.

It was shown that ETS exposure causes destruction in veins with many mechanisms ${ }^{21}$, endothelium-dependant dilatation in healthy young adults and as a result of this dysfunction ${ }^{22,23}$. Endothelium dysfunction was shown in healthy children at the age of 11 exposed to cigarette $\mathrm{smoke}^{8}$. It was reported that carotid intima-media thickness increased with passive smoking in adults ${ }^{24-26}$. Moreover, it was demonstrated that aortic intima-media thickness in newborns exposed to cigarette smoke during pregnancy and carotid intimamedia thickness in young adults increased ${ }^{9,10}$.

Although there are many studies reporting that chronic cigarette smoke exposure affects 
vascular functions in children and adults, there are a limited number of studies related to ventricular functions. In a study conducted on adults, it was demonstrated that acute ETS exposure causes disruptions in the left ventricle diastolic functions ${ }^{27}$. There are no other studies in the literature investigating the left and right ventricular functions in healthy children or children with episodic wheezing in this age group exposed to ETS. In our study, chronic ETS exposure produced no significant changes in the right and the left ventricular functions in children at the age of 1-3; however, these results should be supported by more comprehensive studies.

\section{REFERENCES}

1. Hawthorne MA, Hannan LM, Thun MJ, Samet JM. Protecting Our Children from Second-Hand Smoke. International Union Against Cancer. Geneva, Switzerland: uicc.org; 2008: 1-40.

2. Mannino DM, Moorman JE, Kingsley B, et al. Health effects related to environmental tobacco smoke exposure in children in the United States: Data from the Third National Health and Nutrition Examination Survey. Arc Pediatr Adolesc Med 2001; 155: 36-41.

3. Priest N, Roseby R, Waters E, et al. Family and carer smoking control programmes for reducing children's exposure to environmental tobacco smoke. Cochrane Database Syst Rev 20014; 1: cd001746.

4. Winickoff JP, McMillin RC, Carroll BC, et al. Addressing parental smoking in pediatrics and family practice: A national survey of parents. Pediatrics 2003; 112; 1146-1151.

5. Berrak GS, Özek E, Cebeci D, Karakoç F, Başaran M, Dağlı E. Increased cord-blood eosinophil counts and prenatal exposure to tobacco smoke: a concern for development of atopy early in childhood. Marmara Medical J 2002; 15: 86-91.

6. Chen R, Tavendale R, Tunstall-Pedoe H. Measurement of passive smoking in adults: Self-reported questionnaire or serum cotinine? J Cancer Epidemiol Prev 2002; 7: 85-95.

7. Moss DR, Lucht LA, Kip KE, Reis SE. Acute physiologic effects of secondhand smoke exposure in children. Nicotine Tob Res 2010; 12: 708-714.

8. Kallio K, Jokinen E, Raitakari OT, et al. Tobacco smoke exposure is associated with attenuated endothelial function in 11-year-old healthy children. Circulation 2007; 115: 3205-3212.

9. Gunes T, Koklu E, Yikilmaz A, et al. Influence of maternal smoking on neonatal aortic intima-media thickness, serum IGF-I and IGFBP-3 levels. Eur J Pediatr 2007; 166: 1039-1044.

10. Geerts CC, Bots ML, Grobbee DE, Uiterwaal CS. Parental smoking and vascular damage in young adult offspring: is early life exposure critical? The Atherosclerosis Risk in Young Adults Study. Arterioscler
Thromb Vasc Biol 2008; 28: 2296-2302.

11. ERS task force. Definition, assessment and treatment of wheezing disorders in preschool children: an evidencebased approach. Eur Respir J 2008; 32: 1096-1110.

12. State of California Air Resources Board. Proposed Identification of Environmental Tobacco Smoke as a Toxic Air Contaminant. As Approved by the Scientific Review Panel On June 24, 2005. https://www.arb. ca.gov/regact/ets2006/app3exe.pdf (Accessed on January 2013)

13. Bramer SL, Kallungal BA. Clinical considerations in study designs that use cotinine as a biomarker. Biomarkers 2003; 8: 187-203.

14. Lai WW, Geva T, Shirali GS, et al. Guidelines and standards for performance of a pediatric echocardiogram: a report from the Task Force of the Pediatric Council of the American Society of Echocardiography. J Am Soc Echocardiogr 2006; 19: 1413-1430.

15. Tei C, Ling LH, Hodge DO. New index combined systolic and diastolic myocardial performance: a simple and reproducible measure of cardiac function: a study in normal and dilated cardiomyopathy. J Cardiol 1995; 26: $357-366$.

16. Shedeed SA. Right ventricular function in children with bronchial asthma: a tissue Doppler echocardiographic study. Pediatr Cardiol 2010; 31: 1008-1015.

17. Zeybek C, Yalcin Y, Erdem A, et al. Tissue Doppler echocardiographic assessment of cardiac function in children with bronchial asthma. Pediatr Int 2007; 49: 911-917.

18. Ozdemir O, Ceylan Y, Razi CH, Ceylan O, Andiran N. Assessment of ventricular functions by tissue Doppler echocardiography in children with asthma. Pediatr Cardiol 2013; 34: 553-559.

19. Davenport PW, Cruz M, Stecenko AA, Kifle Y Respiratory-related evoked potentials in children with life-threatening asthma. Am J Respir Crit Care Med 2000; 161: 1830-1835.

20. Massoud MN, El-Nawawy AA, Abou El-Nazar SY, et al. Tumour necrosis factor-alpha concentration in severely asthmatic children. East Mediterr Health J 2000; 6: 432-436.

21. Barnoya J, Glantz SA. Cardiovascular effects of secondhand smoke: nearly as large as smoking. Circulation 2005; 111: 2684-2698.

22. Celermajer DS, Adams MR, Clarkson P, et al. Passive smoking and impaired endothelium-dependent arterial dilatation in healthy young adults. N Engl J Med 1996; 334: 150-154.

23. Otsuka R, Watanabe H, Hirata K, et al. Acute effects of passive smoking on the coronary circulation in healthy young adults. JAMA 2001; 286: 436-441.

24. Howard G, Burke GL, Szklo M, et al. Active and passive smoking are associated with increased carotid wall thickness: The Atherosclerosis Risk in Communities Study. Arch Intern Med 1994; 154: 1277-1282.

25. Diez-Roux AV, Nieto FJ, Comstock GW, Howard G, Szklo M. The relationship of active and passive smoking to carotid atherosclerosis $12-14$ years later. Prev Med 1995; 24: 48-55. 
26. Howard G, Wagenknecht LE, Burke GL, et al. Cigarette smoking and progression of atherosclerosis: The Atherosclerosis Risk in Communities (ARIC) Study. JAMA 1998; 279: 119-124.

27. Dogan A, Yarlioglues M, Gul I, et al. Acute effects of passive smoking on left ventricular systolic and diastolic function in healthy volunteers. J Am Soc Echocardiogr 2011; 24: 185-191. 